\title{
UM OLHAR SOBRE AS RELAÇÕES HUMANAS EM UMA ENTREVISTA DE REFÚGIO
}

\author{
Perspectives on human relations on asylum interviews
}

Hannah Waisman ${ }^{7}$

Giulianna Serricella

A reflexão a seguir é um relato a partir de nossa experiência como Consultoras da Agência das Nações Unidas para Refugiados (ACNUR), atuando junto ao Comitê Nacional para Refugiados (CONARE), no espaço do escritório descentralizado do Comitê na cidade do Rio de Janeiro. O ponto de partida são os registros da nossa memória, baseados na experiência vivida entre o período de julho de 2015 a julho de 2016, durante os contatos com solicitantes de refúgio e refugiados. O espaço institucional do CONARE no Rio de Janeiro possui características físicas e simbólicas condicionadas a atender ao objetivo de abrigar e de facilitar os procedimentos em torno do processo de determinação da condição de refugiado. Tal propósito faz com que o espaço molde ou busque moldar a forma como os sujeitos atuam e se relacionam no mesmo. Com esta reflexão pretendemos articular autores que nos ajudem a pensar quem são esses sujeitos, suas dinâmicas e vivências, em conjunto com a nossa participação e observação enquanto pesquisadoras do assunto e também na função de consultoras.

Isso será construído a partir de um exercício no qual buscamos estabelecer um diálogo entre episódios vividos por nós e pessoas que buscam refúgio no Brasil, o que será retratado a partir de duas percepções: a primeira busca desenhar os desafios ao lidar com as experiências traumáticas de pessoas em situação de vulnerabilidade jurídica e sócio-econômica e seus efeitos; a segunda busca apresentar as dificuldades da função de entrevistadora em não nos limitarmos a nós mesmas e escutarmos ativamente a história da forma como é contada pelo(a) solicitante.

Consultora de Fortalecimento de Capacidades ACNUR. Rio de Janeiro, RJ, Brasil.

2 Consultora de Fortalecimento de Capacidades ACNUR. Rio de Janeiro, RJ, Brasil. 


\section{O preparo (Ato I)}

O momento de preparação para a entrevista envolve questões objetivas voltadas para o caso apresentado pelo solicitante em seu Formulário de Solicitação de Refúgio. A priori, baseamos-nos em sua escrita para moldarmos também a forma como a entrevista será preparada e conduzida. Porém, é no momento de encontro entre o solicitante e o Oficial de Elegibilidade que será possível visualizar de que maneira a mesma se desenrolará ao longo de aproximadas 1 hora e 30 minutos/2 horas. Realizar entrevistas de refúgio envolve colocar dois seres humanos um de frente para o outro, sendo que um deve apresentar seu pedido de refúgio, as razões que motivaram a saída de seu país de origem, e o que poderia acontecer caso retorne, enquanto do outro lado está a Oficial de Elegibilidade que participa da análise do mérito deste pedido.

A realização de uma entrevista é, portanto, um ato que depende de um cuidado e uma técnica que deve ser constantemente aprimorada para que se possa cumprir o objetivo do trabalho de modo respeitoso à pessoa em busca de proteção. Mas acima disso, o que deve prevalecer na entrevista é a sensibilidade para com a pessoa que muitas vezes expõe sua vida e seus momentos mais difíceis na frente de outra, completamente estranha. Assim, a relação interpessoal entre Oficial e entrevistado(a), muitas vezes, se constrói em um momento específico, o qual envolve tanto a posição da entrevistadora (e seus objetivos adjacentes), quanto também o desejo, a ansiedade e a expectativa do(a) solicitante em torno da urgência de sua resposta. É imprescindivel que esses sentimentos sejam manejados durante a entrevista para que não se sobreponham ao objetivo da mesma, que é identificar se a vivência apresentada pela pessoa deve ser compreendida como um caso de refúgio, à luz do ordenamento jurídico brasileiro.

Não obstante, muitas vezes, para que se cumpra este objetivo é necessário estabelecer antes uma relação de confiança entre Oficial e solicitante, ainda que por um período de tempo determinado. Em alguns casos, notamos a urgência de uma pessoa em externalizar os traumas vividos, as marcas da violência e até mesmo os danos físicos sofridos. Além disso, percebemos que, não raros os casos, estamos frente a frente com seres humanos que desabam por completo, seja através do choro, seja através de palavras.

A urgência do(a) solicitante em compartilhar sua história, a angústia demonstrada ao dizer que não quer novamente lembrar de determinados momentos, bem como o choro ou a impaciência durante a entrevista, são alguns exemplos de como ele(a) poderá escolher se posicionar, cabendo ao Oficial estar preparado(a) para lidar com esses momentos e conduzí-los da melhor forma. Pensando ainda na questão do compartilhamento de angústias 
e anseios, não é apenas no momento da entrevista que isso pode se destacar. É comum no atendimento a solicitantes de refúgio, no escritório do Rio de Janeiro, sermos interpeladas sobre desejos, sonhos e pedidos que não podemos solucionar. Pode ser que o(a) solicitante deseje que o momento da entrevista ocorra para que tenha o mérito de seu caso analisado pelo CONARE, uma vez que tem conhecimento da necessidade desse procedimento. Porém, enquanto Oficiais, muitas vezes nos parece que o desejo maior é o de compartilhar sua história, seus anseios, seus medos, sua esperança, dentre outros sentimentos que giram em torno de sua regularização e obtenção do Registro Nacional de Estrangeiro (RNE) no Brasil.

Diante de todas as dificuldades, barreiras linguísticas, emocionais, psicológicas, culturais, entre outras, como ignorá-las? Cabe a reflexão: será que o governo brasileiro tem o papel de compreender os anseios dos solicitantes? Se sim, em qual medida e com quais limites?

Essas situações que, muitas vezes sentimos como "urgências" expostas por outros, ainda que venham acompanhada da nossa tarefa em administrar a forma como esses relatos vão ser mobilizados e traduzidos em uma recomendação, em diferentes momentos nos fazem repensar sobre a condição humana - a dele e a nossa.

\section{Encontros e desencontros de uma entrevista (Ato II)}

Desconforto - uma sensação que se repete e muitas vezes permanece durante o momento do encontro entre o(a) Oficial e o(a) solicitante, no espaço e no tempo de uma entrevista na qual se busca proceder à análise do pedido de refúgio e que muitas vezes é marcado por relatos de experiências traumáticas e de extrema violência. Esse desconforto pode ser expresso de muitas formas. Em alguns momentos ele se dá no silêncio, em outras pelo barulho do bater dos pés no chão, ou ainda pelos movimentos corporais contínuos e pelas falas aceleradas.

Fatos consagrados nas áreas do conhecimento ligadas à psicologia e à medicina demonstram como as experiências traumáticas podem levar anos ou até mesmo uma vida inteira para serem reveladas. No âmbito do procedimento de elegibilidade, os autores Gejer e Ellis notam que para compensar revisitar esses eventos estressantes, os indivíduos podem criar mecanismos de proteção, tais como evitar contar certos fatos ou contá-los de modo dissociado, a fim de manejar memórias indesejadas. Nota-se assim, que existem diversos fatores que interferem na construção social do migrante, em particular no reconhecimento da sua situação de refúgio. As experiências vivenciadas, até mesmo as que poderiam ser identificadas como informações que fortaleceriam o pedido de refúgio de alguém, muitas vezes permanecem sem ser ditas sob 
tais circunstâncias. Ainda, em algumas situações, a mobilização da opinião pública em torno da imagem e da percepção da pessoa que migra se altera e traz consequências que acompanham o(a) solicitante antes, durante e após o momento de sua entrevista.

É importante compreender que os fatos descritos acima não devem ser lidos como elementos que influenciam negativamente a análise dos casos, pois representam a vertente humana dos processos - e sem esta compreensão, as análises técnicas podem permanecer incompletas.

\section{Ato III}

Entrevista em inglês, estamos na introdução. Este é o momento voltado para explicar ao solicitante o objetivo da entrevista, como seu caso será analisado e também esclarecer quaisquer dúvidas relacionadas ao processo. Li o Artigo $1^{\circ}$ da Lei $n^{\circ}$ 9.474/1997. O solicitante acena com a cabeça no movimento de quem compreende o que está sendo dito. Noto que ele olha para os lados. Não acho que ele esteja concentrado. Busco saber se ele está acompanhando o que digo, pergunto, ele indica que compreendeu tudo o que disse. Qual é o limite para suspeitar que ele talvez não esteja entendendo aquilo que digo? Preciso continuar a entrevista, ele diz que não tem dúvidas. A entrevista avança. Olho seu Formulário de Solicitação de Refúgio, a pergunta de número 12 pede que o solicitante indique e justifique "os motivos pelos quais você precisa da proteção internacional como refugiado no Brasil". Ele havia marcado o " $\mathrm{X}$ " em dois dos motivos possíveis. Pergunto o porquê. Ele explica, e assim esclarece que havia marcado os motivos nos quais viu a caracterização de seu agente de perseguição. Eu não. Eu busco ver os motivos que moldam o possível dano que ele irá sofrer caso retorne. Eu busco ver o que motiva a fuga e o que aconteceria depois. Sua resposta me chamou a atenção, era tão diferente da minha. Pensei que havia Ihe explicado a lei, a definição daquele que poderia ser reconhecido como refugiado. Mesmo assim, na resposta que ele havia me dado, quem sobressaia era aquele que o perseguia, e não ele. Ele não parecia se identificar nesta questão. Eu pensei que ele não estava relacionando o Formulário à introdução da Entrevista. A entrevista continuou e ele pôde expressar de maneira consistente e coerente seus temores, motivos e a perseguição que o trouxeram para o Brasil. Por fim, a entrevista terminou e continuei pensando sobre ela. (Relato Pessoal da Oficial de Elegibilidade a partir de entrevista realizada e reflexões posteriores)

A linguagem necessária para possibilitar o momento vem acompanhada de sua diversidade cultural, social, política. Em todos os momentos que envolvem uma entrevista e a análise de um caso buscamos perceber estes fatores, de modo a tentarmos adaptar nossa linguagem e as maneiras de se expressar conforme as especificidades do(a) solicitante que conseguimos identificar. 
Porém, é possível garantir um entendimento completo do que está sendo dito pela Oficial por parte do(a) solicitante? E o oposto, por sua vez, também seria possível?

\section{Ato IV}

Como se portar diante de uma mulher de aproximadamente 50 anos, que está separada de seus filhos há mais de quatro anos? Sua solicitação de refúgio foi indeferida pelo CONARE e neste momento ela aguarda pela análise de seu recurso pelo Ministro da Justiça. A solicitante deseja encontrar seus filhos e pensa em todos os meios possíveis para conseguir realizar isto. No entanto, não existe documentação para que uma mulher como ela consiga tornar este desejo possível. Ela tentou obter visto de outros países. Negado. Ela agora aguarda a resposta de um recurso apresentado ao Ministro da Justiça. Em todos os lugares que ela vai pedem que ela aguarde. Ela não parece aguentar mais que lhe peçam para esperar. Ela sai do escritório mais uma vez sem a resposta que deseja ouvir, sem a solução que deseja. Antes de sair, contudo, a mesma rebate e argumenta as respostas que recebe. As palavras, ainda que ditas, não querem ser compreendidas. Compreendê-las e aceitá-las significa não encontrar seus filhos agora. A angústia de sua idade faz com que ela só deseje sair. As respostas negativas são questionadas pela solicitante, que nos indaga sobre sua liberdade de movimento, de ir de vir.

Nós não conseguimos dar ao outro a informação que deseja e, ainda que seja uma mulher com a idade aproximada de nossas mães, a barreira ética e profissional limita o envolvimento emocional com esta situação. Os desejos são muitos, de ambos os lados, porém ainda assim incompreensíveis.

\section{Final}

Essa foi uma breve reflexão e um exame crítico sob a ótica de nossa posição enquanto pesquisadoras e consultoras. Essa dupla perspectiva é um resultado de uma função técnica que não está dissociada da relação interpessoal entre diferentes sujeitos e que engloba relações hierárquicas distintas. Buscamos com isso, contribuir com um relato sobre a importância da produção de conhecimento de modo interdisciplinar na área da migração e, principalmente, a partir da aproximação e escuta ativa entre os diferentes sujeitos. Frente a um cenário muitas vezes marcado pela desinformação, pela angústia e pela expectativa por uma vida digna na qual os sonhos possam ser realizados, as redes articuladas em diferentes esferas se mostram essenciais para garantir o fluxo de informações, tornando o canal para a busca do refúgio, bem como seu sistema de proteção, um processo mais justo, transparente e menos doloroso para as pessoas envolvidas. 


\section{Referências}

ACNUR Brasil. Coletânea de Instrumentos de Proteção Nacional e Internacional de Refugiados e Apátridas. Brasília, DF, 2013. Seção Publicações. Disponível em: <http://www.acnur.org/t3/fileadmin/scripts/doc.php?file=t3/fileadmin/ Documentos/portugues/Publicacoes/2012/Lei_947_97_e_Coletanea_de_ Instrumentos_de_Protecao_Internacional_de_Refugiados_e_Apatridas $>$. Acesso em: 05.06.2016.

BARRETO, Luiz Paulo Teles Ferreira (org.). Refúgio no Brasil: a proteção brasileira aos refugiados e seu impacto nas Américas. 1. ed. - Brasília: ACNUR, Ministério da Justiça, 2010.

CAGGIANO, Sergio; TORRES, Alicia. Negociando categorías, temas y problemas: Investigadores y organismos internacionales en el estudio de la migración indígena. In FELDMAN-BIANCO, Bela; RIVERA SÁNCHEZ, Liliana; STEFONI, Carolina; VILLA MARTÍNEZ, Marta Inés (comps.). La construcción social del sujeto migrante en América Latina: prácticas,representaciones y categorías. FLACSO Serie Foro; CLACSO Colección Cátedra Iberoamericana de Estudios sobre Migraciones, 2011.

GEJER, Julian; ELLIS, Adam. Post-Traumatic Stress Disorder and the Refugee Determination Process in Canada: Starting the discourse. New Issues in Refugee Reasearch, Research Paper n. 270, 2014.

MOULIN, Carolina. A construção do refugiado no pós-Guerra Fria: dilemas, complexidades e o papel do ACNUR. Carta Internacional, v. 7, n. 2, jul.-dez. 2012, p. 23-49. 